\title{
Physical Properties of Gold Electrodeposits and Their Effect on Thickness
} Measurement*

\author{
$\frac{\text { Stewart J Hemsley }}{\text { Engelhard-CLAL (Singapore) Pte Ltd }}$
}

The relative effectiveness of methods available for measuring the thickness of gold electrodeposits is reviewed; and the methods selected for assessing deposits in electronic connectors discussed. Many factors influence the interpretation of results for gold electrodeposits, the most significant being deposit density and the factors which influence this are explored.

The science of thickness measurement has advanced significantly in the past decade and measurement of precise areas on complex shaped components can now be carried out non-destructively and with reproducible results. This ease of measurement has led to increased control of process costs for the electroplater and more precise specification of work requirements from the designer/customer to the electroplater/subcontractor.

Many factors can influence the quality and thickness of acid gold electrodeposits (1-3). With high value precious metals, such as gold, the need for control of cost and metal consumption is amplified and is the focus of attention for both platers and accountants (4). This can often lead to discussions between the electroplater and the customer on what is the exact thickness and whether it conforms to the original specification.

This paper indicates the difficulties encountered in thickness measurement and highlights the factors which need to be considered when interpreting results. Particular attention is paid to the situation faced by the producer of gold plated electronic connectors not only in the actual process of thickness measurement but in the definition and control of specifications to maximize gold savings.

[*] This paper is based on that presented by the author at the Second European Precious Metals Conference, organised by Eurometaux (Association Européenne des Métaux), Lisbon, May 1995.

\section{TECHNIQUES FOR MEASURING THICKNESS}

Many destructive and non-destructive methods for thickness measurement have evolved over the years. Some of these methods are time-consuming, but measurements can be achieved within a matter of seconds with others. The major methods currently available are outlined below.

The purpose of this review is to highlight the reasons for the methods being either used or discarded for thickness measurements on electronic connectors. The methods indicated do not represent an exhaustive list, but it is clear that a wide variety does exist (5). Comments are given on the suitability of each method for practical production environments.

\section{Microsectioning}

This is one of the fundamental methods and very simple in theory (5-7). The measurement of the physical thickness by optical microscopy is regarded as the referee method to evaluate the accuracy of others. In practical terms, the procedure is straightforward. The sample is overplated with copper and cut close to the measuring point, then mounted in resin with the plated layer at $90^{\circ}$ to the horizontal. The sample is then polished to give a uniform smooth surface, with final polishing performed using a 0.5-0.25 micron diamond polishing compound. This provides a virtually flat surface for examination under an optical microscope at a magnification of between 800 and 1000 times. The surface is lightly etched to highlight and clearly define the gold layer.

The physical aspects of this method can lead to errors 
resulting from misalignment of the section from the $90^{\circ}$ angle $\left(10^{\circ}=2 \%\right.$ error). Careless polishing can smear the edges, and distortion resulting from inadequate support of the component can add to the error. The limitations of optical microscopy in terms of resolution can introduce an error of around 0.2 microns per edge measured, and this is the major source of error in the technique. The use of a Scanning Electron Microscope (SEM) can reduce this error to less than 0.05 microns, making the method an accurate means of thickness determination, but in the practical world of electroplating there are few platers who can justify the need for an SEM.

\section{Weight Gain}

This is a simple technique having a very high degree of accuracy (8). However, in practice it is almost impossible to implement as it necessitates weighing the clean dry part prior to electroplating and then weighing to constant weight. The weight of a deposit can be translated into a thickness measurement by calculation using the deposit density and known surface area. For example, the density of pure gold is $19.3 \mathrm{~g} / \mathrm{cc}$ and a deposit weighing $19.3 \mathrm{~g}$ on an area of $1 \mathrm{~cm}^{2}$ has a thickness of 1 $\mathrm{cm}$. This is the principle used in all thickness calculations; and the micron is becoming the unit in common use, but in some countries the microinch is favoured. This method relies on the deposit density being known, and factors influencing this are discussed later.

This method suffers from the major drawback that it gives the overall weight of gold on the component rather than an indication of the thickness distribution, as the above method of calculation assumes that the distribution is totally uniform. In practical plating situations, thickness often varies significantly across a plated part as a result of current distribution patterns governed by the shape and orientation of the part in relation to the anode. In addition, precise surface areas are often unknown.

A major benefit is that this method does give the total weight of gold used on a particular component and this can be used for inventory control purposes. The increase in weight will only, however, give an accurate measure of thickness if the plating bath has been kept fully under statistical process control to ensure constant output and quality.

\section{Dissolution}

This is again a simple and indeed very accurate method (9), which will also indicate the weight of gold on a particular part and is usually relevant to measurements on electronic connectors. Its major disadvantage is that it is, by its very nature, a destructive technique and only really finds application in cases of dispute. The accuracy of measurement depends upon the sophistication of the analytical techniques available for the resultant solution, but less than a $0.5 \%$ error is certainly achievable.

There are many variations of this technique, and, for example, initial dissolution of the substrate can eliminate difficulties in the analytical methods used for the resultant gold solution. However, this method suffers from the same drawback as weight gain in that it does not directly relate to thickness at a given point, but gives the total weight of gold on the component. This weight is then translated into a mean thickness value based on the physical properties of the alloy deposited.

\section{Coulometric}

This is another destructive method of thickness testing, in which the plated layer is electrolytically removed from its substrate by the passage of electric current under controlled conditions; in fact the reverse of electroplating $(10,11)$. The instruments are calibrated for a particular deposit and its characteristics to take account of the efficiency of deplating.

With simple acid gold electrolytes, the method is reasonably accurate, within $5 \%$. As alloy compositions vary and become more complex, the need for accurate calibration becomes more critical and the reliability of the resultant figures is very dependent upon this calibration and the standards used. In practical terms the method suffers by being destructive but it is easier to use than the other destructive methods and generally less time consuming.

\section{Profilometric}

This method can be applied for measuring 'step' height and comparing this with substrate height (12). The physical thickness of the deposit is measured using a Surfometer. This instrument incorporates a diamond stylus which is constrained to traverse a short distance across a surface. When the stylus encounters a physical step or unevenness in the surface, its position in the vertical plane is changed. The signal generated by the movement of the stylus is amplified and fed to a chart recorder which displays a step on the chart. From this data the step height above the surface may be determined.

\section{Beta-Backscatter}

Beta-backscatter (BBS) is a convenient non-destructive method for thickness measurement (13-15). The principle upon which it is based is that a source of beta particles is directed as a collimated beam through an aperture onto the plated component. A proportion of these particles is returned back from the plated coating 
through the aperture to penetrate the thin window of a special Geiger Muller (GM) tube. The gas in the GM tube ionises causing a momentary discharge across the tube electrodes. This discharge, in the form of a pulse, is measured by an electronic counter. The microprocessor compares this backscatter with that from a sample of the base material and that from the coated material and translates this onto a meaningful indication of thickness, or weight per unit area.

By selecting beta sources of different intensity, a wide range of thicknesses can be measured for gold, i.e. ${ }^{147} \mathrm{Pm}$ for $0.5-2.0$ microns, ${ }^{204} \mathrm{Tl}$ for 2.5-10.0 microns, and ${ }^{90} \mathrm{Sr}$ for 5.5-35.0 microns.

Beta-backscatter works most effectively on flat surfaces, where a direct contact can be made between the surface and the detector probe. For alloy golds the method relies heavily on a constant deposit composition and the technique also requires calibrated standards from the same source as the plated part to be measured.

The technique works by comparing data with the calibrated standard but does not identify layers, it merely compares deposit densities; hence if the density varies as may be the case with an alloy deposit, then the percentage error in the thickness measurement will increase accordingly. Adherence to the health and safety regulations for radioactive sources means that the administration costs for this method are high.

\section{$X$-Ray Fluorescence}

$\mathrm{X}$-Ray fluorescence (XRF) is a technique widely used for the assessment of electronic components. A high energy beam of incident $\mathrm{X}$-rays is directed onto the coated object in question using a precision collimator. The incident X-ray beam produces photons (or fluorescence) from most materials within its range and each element fluoresces at a characteristic energy level $(16,17)$. The intensity of the signal at a given energy level is proportional to the thickness of the deposited element (eg copper, silver or gold). With the use of standards, the coating thickness can be determined.

This method has major advantages over betabackscatter in that the measurement is contact free and can therefore be used on parts having intricate and complicated shapes. In addition, the health and safery requirements are more acceptable as radiation is only present when the instrument is in use, as compared with beta-backscatter where radiation is ever present. This method does, however, suffer from the same drawbacks as beta-backscatter in that it is heavily influenced by changes in deposit structure and alloy composition. The most significant factor being a change in deposit density.

\section{METHODS USED FOR ASSESSING ELECTRONIC CONNECTORS}

The two systems most commonly used in assessing gold plating on electronic connectors are XRF and dissolution. $\mathrm{XRF}$ is used for non-destructive thickness measurement of precisely defined areas. Dissolution is used to determine the total weight of gold per component. It is important to carry out both of these tests as one alone cannot give a reliable assessment of both gold consumption and compliance with thickness specifications. A component with the correct weight of gold per part may fall outside the thickness specification as a result of poor registration of any selective plating or inconsistent thickness distribution across the part; whereas a component with an apparently low weight of gold may conform to the thickness specification as a result of variable distribution of gold thickness. Thus, if the specified XRF measurement point is in the thickest part of the deposit, caused by this being in the high current density area, other areas may be significantly thinner.

In the connector industry specifications are usually well defined, but they can still lead to some ambiguity in interpretation. Typical thickness specifications fall into the range 0.1-2.5 microns of gold. Low performance connectors fall into the 'flash gold' category of 0.1 micron, with most high performance connectors in the range 0.75-1.25 microns. In all cases, gold is plated onto a nickel undercoat. The accuracy of the measurement method used for thickness determination needs careful examination, as there are many factors which could influence the validity of the results obtained. The principal factors which need to be clarified and agreed are outlined below.

\section{Calibration/Standards}

All instrumental techniques of measurement rely on accurate and meaningful standards for calibration; XRF is no exception, and standards are supplied by the manufacturers. These standards are traceable back to national bureaux and institutes and meet the needs for quality management systems. For more complex alloys such as low carat gold, special standards often need to be prepared and verified to enable a meaningful calibration to be performed.

\section{Critical Area/Measurement Point}

Non-destructive testing has enabled measurement points to be clearly defined and to meet performance 
needs; the area to be plated is based on function needs together with the decorative appearance required.

\section{Distribution of Thickness}

The distribution of thickness of the deposits obtained from all plating solutions is a contributory factor in assessing cost, and this factor is particularly important for gold, bearing in mind its intrinsic value. The gold electrolyte should therefore be selected to give the best distribution pattern and the tank design should be optimized to suit this chemistry.

\section{Specifications}

In defining specifications, the critical areas and measurement points need to be clearly defined and agreed by both the plater and customer. Non-critical areas are potential cost savers as gold can be deposited only where needed. Having agreed a specification, it is then the plater's responsibility to ensure that the thickness is within a defined maximum and minimum.

\section{Alloy Composition}

This has a significant impact in low carat gold electrodeposits (18) but does not have such a major influence in the thickness measurement of the hard acid gold deposits used in electronic connectors. In these processes the percentage of cobalt, or nickel, is controlled within a narrow band and usually falls within $0.1-0.3 \% \mathrm{w} / \mathrm{w}$ in the plated deposit. However, co-deposition of these transition metals and other elements, such as $\mathrm{K}, \mathrm{Na}$ and $\mathrm{C}$, and organics can lead to changes in structure which significantly affect the thickness measured (19).

\section{Structure}

If the deposit structure is inconsistent then the assumptions made in the calculation of thickness by non-destructive techniques will not be valid.

\section{Carat}

This factor is of course very significant, and standards for the correct carat need to be used to ensure calibration is meaningful. The standards should also, ideally, be produced and verified using the same electrolyte as the solution used to plate the production items.

\section{Deposit Density}

This is perhaps the most significant factor, as with many processes the density varies with the alloy composition and the alloying metals used together with electrolyte design. Table 1 illustrates the relationship between carat, electrolyte composition and density.

With an acid hard gold, the inclusion of other materials within the deposit has been well documented (1923) and obviously has a significant effect on the theoreti$\mathrm{cal}$, and indeed the actual, deposit density. Table 2 gives relevant information on density of deposits. Figure 1 indicates the components of density for a gold deposit, based on the formula for density equal to 100 divided by $(x /$ density ' $x$ ' $+y /$ density ' $y$ ': where $x=\%(w / w)$ element $\mathrm{x}$ in deposit, $\mathrm{y}=\%(\mathrm{w} / \mathrm{w})$ element $\mathrm{y}$ in deposit, etc).

Table 1 Deposit density from various electrolytes

\begin{tabular}{|c|c|c|c|c|}
\hline Deposit & $\begin{array}{l}\% \text { by weight of } \\
\text { major elements }\end{array}$ & $\begin{array}{c}\text { Carat } \\
\text { (nominal) }\end{array}$ & Electrolyte & $\begin{array}{l}\text { Measured Density } \\
\text { g/cc }\end{array}$ \\
\hline Pure Gold & Au: $99.9 \%$ & 24.0 & Phosphate & 19.3 \\
\hline Acid Hard Gold & Au: $99.2 \%$ & 23.7 & Citrate & 16.5 \\
\hline $\mathrm{Au} / \mathrm{Cu} / \mathrm{Cd}$ & $\begin{array}{c}\text { Au: } 75.0 \% \\
\text { Cu: } 20.0 \% \\
\text { Cd: } 5.0 \%\end{array}$ & 18.0 & Cyanide & 15.0 \\
\hline $\mathrm{Au} / \mathrm{Cu} / \mathrm{Cd}$ & $\begin{array}{l}\text { Au: } 58.3 \% \\
\text { Cu: } 35.7 \% \\
\text { Cd: } 6.0 \%\end{array}$ & 14.0 & Cyanide & 13.5 \\
\hline $\mathrm{Au} / \mathrm{Ag} *$ & $\begin{array}{l}\text { Au: } 50.0 \% \\
\text { Ag: } 50.0 \%\end{array}$ & 12.0 & Cyanide & 10.0 \\
\hline $\mathrm{Au} / \mathrm{Cu} *$ & $\begin{array}{l}\text { Au: } 75.0 \% \\
\text { Cu: } 25.0 \%\end{array}$ & 18.0 & Cyanide & 12.0 \\
\hline
\end{tabular}

* For Au/Ag and Au/Cu deposits other elements are also present in small quantities; hence percentages quoted for $\mathrm{Cu}$ and $\mathrm{Ag}$ are estimates only, based on gold percentage, and obtained by difference. 


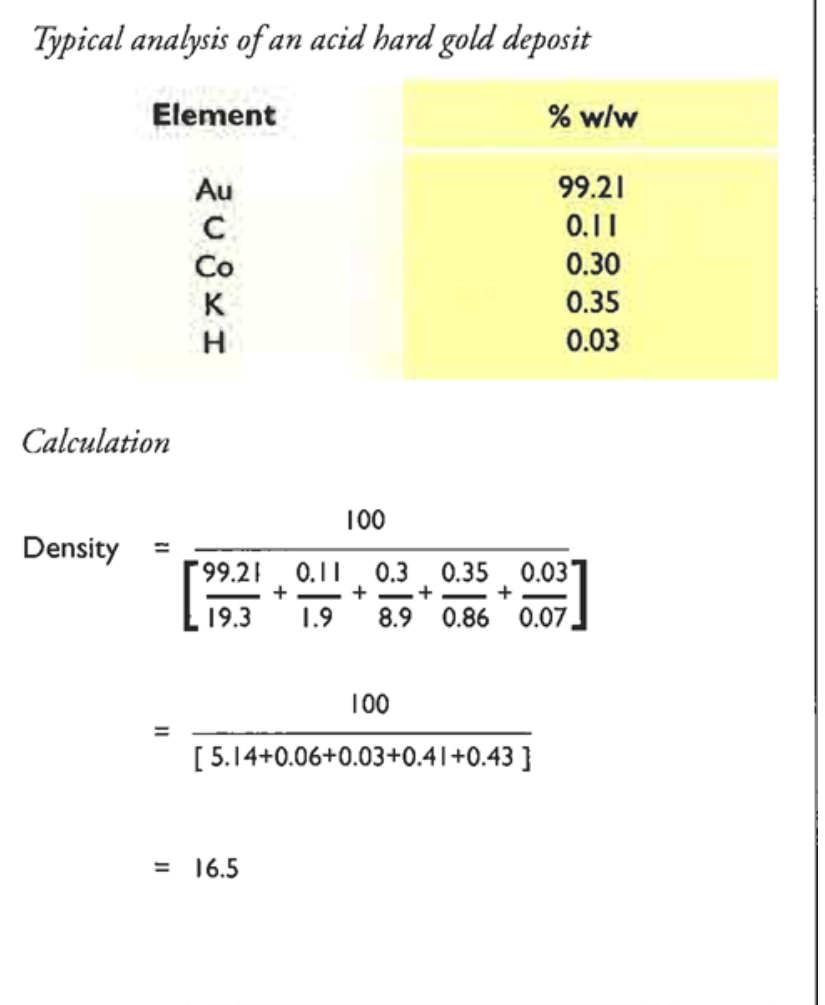

Figure 1 Calculation of density for gold deposits

This theoretical density is close to that achieved with a modern acid gold electrolyte and previously reported by J. Mayne (24). Very small percentages by weight of lighter elements can significantly affect the density. Sodium, potassium, hydrogen, oxygen and nitrogen have very low densities and consequently influence the overall density of a gold deposit more dramatically than heavier elements, such as carbon, cobalt, iron, nickel, etc. Even for a pure substance, the density can vary dependent on crystal form and structure (the figures for three forms of carbon are given in Table 2). Hence, a theoretical calculation of deposit density may not always be accurate for a real electrodeposit. In our calculations (Figure 1) we have used the densities for elements as listed in Table 2 (25), and these must be regarded merely as best estimates.

The industry has tended to be conservative with respect to the deposit density required for acid gold and the debate ranges as to whether the density should be $17.5 \mathrm{~g} / \mathrm{cc}$ or $16.5 \mathrm{~g} / \mathrm{cc}$, with many manufacturers settling on the safe middle ground of $17.0 \mathrm{~g} / \mathrm{cc}$ for measurement purposes.

The data available on deposit densities is fairly limited, particularly that which relates to change in deposit density with change in current density, temperature, $\mathrm{pH}$, and the other basic process parameters which are known to vary in a real installation. Current density has a signifi-
Table 2 Density of elements sometimes found in gold electrodeposits

$\begin{array}{ccc}\text { Element } & \text { Symbol } & \begin{array}{c}\text { Density } \\ \text { g/cc }\end{array} \\ \text { Gold } & \mathrm{Au} & 19.3 \\ \text { Silver } & \mathrm{Ag} & 10.5 \\ \text { Copper } & \mathrm{Cu} & 8.9 \\ \text { Cobalt } & \mathrm{Co} & 8.9 \\ \text { Nickel } & \mathrm{Ni} & 8.9 \\ \text { Cadmium } & \mathrm{Cd} & 8.6 \\ \text { Indium } & \mathrm{In} & 7.3 \\ \text { Carbon } & \mathrm{C} & \\ \text { : Diamond } & & 3.51 \\ \text { : Graphite } & & 2.25 \\ \text { : Amorphous } & & 1.9 \\ \text { Oxygen } & \mathrm{O} & 1.15 \text { (liquid) } \\ \text { Sodium } & \mathrm{Na} & 0.97 \\ \text { Potassium } & \mathrm{K} & 0.86 \\ \text { Hydrogen } & \mathrm{H} & 0.07 \text { (liquid) }\end{array}$

cant effect, and the range can be very wide across a typical connector. For a typical acid hard gold plating bath (see Table 3), it is known that cobalt and potassium percentages vary with current density so it is not too much of an assumption to suggest that hydrogen, oxygen and nitrogen contents may also be subject to variation.

There is a school of thought which suggests that at low thickness, the actual deposit density is influenced largely by the substrate and the degree of activation and microetching. The theory being that the number of growth sites for the initial electrocrystallization will vary and thus influence the growth and structure of the gold

Table 3 A typical acid hard gold plating bath

$\begin{array}{ccc}\text { Component } & \text { Unit } & \text { Range } \\ \text { Gold } & g / 1 & 2.0-10.0 \\ \text { Citrates/Phosphates } & g / 1 & 100-150 \\ \text { Cobalt/Nickel } & g / 1 & 0.25-2.0 \\ \text { Additives } & \mathrm{g} / 1 & 0.25-2.0 \\ \text { Surfactant } & \mathrm{m} / 1 & 0.1-5.0 \\ \mathrm{pH} & & 4.0-5.0 \\ \text { Temperature } & { }^{\circ} \mathrm{C} & 30-60\end{array}$


Table 4 Potential cost savings for selected gold deposits

$\begin{array}{lc}\text { Deposit } & \begin{array}{c}\text { Density } \\ \text { g/cc }\end{array} \\ \text { Pure gold } & 19.3 \\ \text { Acid Gold } & 16.5 \\ \text { Alloy Gold } & 15.0 \\ \text { Au Cu Cd } & \text { (Weight of alloy per cc) } \\ & 11.2 \\ \text { (I8 Carat) } & \text { (Weight of Gold per cc) }\end{array}$

electrodeposit in its initial stages. As growth progresses, the solution characteristics overcome this initial surface related growth pattern, and the density becomes more akin to the standard solution expectations.

It is almost impossible to measure the precise deposit density on an actual connector. Most densities quoted are based on those obtained in simulated conditions on laboratory test pieces, and the direct relevance of these results to what happens in practice is not known with precision. There is, however, increasing evidence to support the use of a deposit density of around $16.5 \mathrm{~g} / \mathrm{cc}$. Whether or not a company chooses to implement this, is largely its own responsibility in liaison with its customers. Cost savings resulting from agreed changes can then be shared with customers (see Table 4). Whatever methods are used, the importance of the need for process control to maintain constant composition cannot be over emphasized. Careful choice of electrolyte to achieve uniformity of deposit is also important.

\section{CONCLUSIONS}

Thickness measurement reliability is essential to prevent costly overplating of gold deposits. The limitations of the technique of measurement need to be clearly understood when comparing results. Deposit density can have a significant effect and must be taken into account when evaluating results obtained by non-destructive thiclzness testing. Process control to ensure constant composition is an essential part of a well run plating shop.

\section{ACKNOWLEDGEMENTS}

The author thanks $\mathrm{Mr}$ Robin Birtles, Fischer UK Limited, and Mr Terry Latter, CMI Europe Limited, for their assistance in the preparation of the material

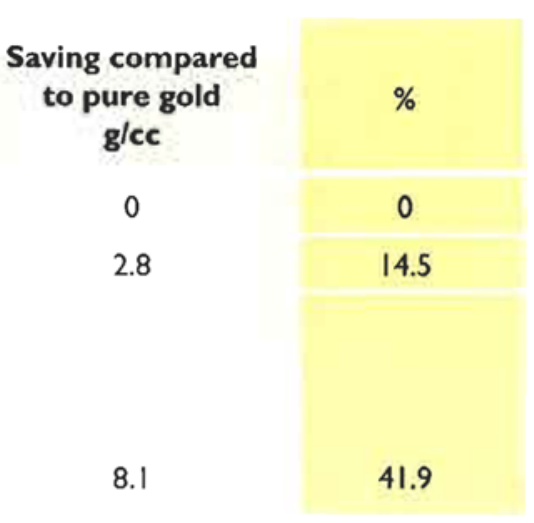

for this paper, and Engelhard-CLAL for providing the opportunity to publish the resulting account.

\section{ABOUT THE AUTHOR}

Stewart Hemsley is the Development Manager for Engelhard-CLAL (Singapore) Pte Ltd and has been involved in the electroplating industry for 22 years.

\section{REFERENCES}

1 P. Wilkinson, Gold Bull, 1986, 19, 75

2 P. Wilkinson, Trans. Inst., Metal Finishing, 1981, 59,57

3 S.J. Hemsley, Proc.Asia Pacific Interfinish, Singapore, November 1990, pp. 27.1-27.15

4 S.J. Hemsley, Finishing Science (Taiwan), May 1992, Issue 135, pp. 135-144; ISSN 1016-7382

5 T.D.T. Latter, Product Finishing, 1980, 33, 9 (updated 1985)

6 G.A. Wilson, Metal Finishing, 1964, 62, 50

7 T. Cullen and P. Petruna, Plating, 1967, 54, 1939

8 F.H. Reid and W. Goldie, Gold Plating Technology, 1974, 28, 372

9 D.G. Foullke and F.R. Crane, 'Electroplaters' Process Control Handbook', Reinhold, New York, 1963

10 T.D.T. Latter, private communication

11 P.C. Baldwin, Plating, 1970, 57, 927

12 W.A. Judge, 'Engineering Precision Measurements', 3rd Edition, Chapman and Hall, London, 1957, Chapter 13

13 T.D.T. Latter, Product Finishing, November 1982

14 B.B. Joffe and R.S. Modjeska, Metal Finishing, $1963,61,44$

15 R.L. Cooley, Plating, 1970, 57, 111

16 T.D.T. Latter, Circuit World, 1983, 10, No. 1 
17 E.P. Bertin and R.J. Longobucco, Metal Finishing; $1962,60,42$

18 S. J. Hemsley and T. Jones, Forum on Alloy Gold, Hong Kong Productivity Council, November 1992

19 S.J. Hemsley and R.V. Green, Trans. Inst. Metal Finishing, 1991, 69, 149

20 L.. Holt and J. Stanier, Trans. Inst. Metal Finishing, 1972, 50, 24

21 K. Whitlaw and J.W. Souter, 'Connectors '83',
Institute of Metal Finishing, 1983

22 K. Whitlaw, J.W. Souter, I.S. Wright, M.C. Nottingham and I.M.F. East, 'Connectors '85', Institute of Metal Finishing, East Midlands Branch, 1985

23 Ch.J. Raub, A. Knodler; and J. Lendvay, Plating and Surface Finishing, January 1976

24 J. Mayne, Trans. Inst. Metal Finishing, 1987, 65, 10

25 'Handbook of Chemistry and Physics', 55th Edition, CRC Press, Boston, USA, 1975 